Original Research Article

\title{
Evaluation of anti-depressant activity of zinc and vitamin B6 as adjuvants to fluoxetine in an animal model of depression
}

\author{
Sunitha T. ${ }^{1}$, Prabhat G. ${ }^{2}$, Kiran Kishore ${ }^{3}$, L. Venu Madhavi*3
}

${ }^{1}$ Department of Pharmacology, Government Medical College, Siddipet, Telangana, India ${ }^{2}$ Department of Pharmacology, Gandhi Medical College, Secunderabad, Telangana, India ${ }^{3}$ Department of Clinical Pharmacology and Therapeutics, Nizams Institute of Medical Sciences, Punjagutta, Hyderabad, Telangana, India

Received: 12 November 2018 Accepted: 19 November 2018

*Correspondence to: Dr. L. Venu Madhavi, Email: madhu2034@ yahoo.co.in

Copyright: (C) the author(s), publisher and licensee Medip Academy. This is an openaccess article distributed under the terms of the Creative Commons Attribution NonCommercial License, which permits unrestricted noncommercial use, distribution, and reproduction in any medium, provided the original work is properly cited.

\begin{abstract}
Background: Depression is a significant public health problem. It is estimated by the World Health Organization that more than 300 million people suffer from depression globally. Micronutrient deficiencies have been constantly linked to depression. The currently used drugs in treatment of depression modulate the excitatory and/or the inhibitory neurotransmission pathways through different mechanisms. The aim of the present study was to compare the antidepressant effect of the micronutrients, zinc and vitamin B6, as adjuvants to Fluoxetine in Albino Wistar rats.

Methods: Eighteen albino wistar rats of 180-280grams of either sex were used in the study to evaluate the anti-depressant activity after approval from the Institutional Animal Ethics Committee. They were divided into three groups of six rats each (3 groups). Group 1 was control group which received only distilled water, group 2 was standard group which received fluoxetine and group 3 was test group which received zinc, vitamin B6 and fluoxetine. The anti-depressant activity was measured using the forced swimming test (FST) which works on the principles of behavioral despair. Data analysis was done using IBM SPSS software, version 25.0 and $\mathrm{p}$ value $<0.05$ was considered statistically significant. Results: The rats of the standard and test groups had latency periods' means of $268.83 \pm 30.16,126.17 \pm 22.33$ and $125.33 \pm 11.86$ on $254.83 \pm 13.00,118.67 \pm 8.16$ and $127.17 \pm 6.68$ seconds on days 1,7 and 14 respectively $(\mathrm{p}<0.001)$ and the rats of the standard and test groups had despair periods' means of 177.00 \pm 7.46 , $95.17 \pm 10.65,93.17 \pm 7.47$ and $167.17 \pm 14.82,97.33 \pm 7.63$ and $87.50 \pm 4.1$ seconds on days 1,7 and 14 respectively ( $p<0.001$ ).

Conclusions: Supplementation of zinc and vitamin B6 to the standard treatment fluoxetine yielded better anti-depressant activity than fluoxetine alone in rats subjected to stress.
\end{abstract}

Keywords: Animal model, Depression, Fluoxetine, Forced swim test, Vitamin B6, Zinc

\section{INTRODUCTION}

Depression is a significant public health problem. It is estimated by the World Health Organization that more than 300 million people suffer from depression globally. ${ }^{1}$ Micronutrient deficiencies have been constantly linked to depression. ${ }^{2}$ It has been postulated that zinc and vitamin B play an important role in modulating the excitatory $\mathrm{N}$ Methyl D-Aspartate (NMDA) receptor and the inhibitory neurotransmitter, Gamma Amino Butyric Acid (GABA). ${ }^{3-}$ 6 The NMDA receptor has been implicated in various forms of cortical functioning and depression, therefore it appears that decreased levels of these nutrients may produce abnormal NMDA activity and subsequent abnormal behavior in depression., ${ }^{2,7}$ The currently used drugs in treatment of depression modulate the excitatory and/or the inhibitory neurotransmission pathways through different mechanisms. 
The aim of the present study was to compare the antidepressant effect of the micronutrients, zinc and vitamin B6, as adjuvants to fluoxetine versus fluoxetine alone in albino wistar rats.

\section{METHODS}

\section{Animals}

Adult albino wistar rats were used in the study and were obtained from the Central Animal House, Gandhi Medical College, Secunderabad. The animals were stabilized for 1 week, maintained under standard conditions at room temperature, $60 \pm 5 \%$ relative humidity and 12 hour light and dark cycles. They were given a standard pellet diet and water ad-libitum. The animals were given free access to food and water.

\section{Ethics}

The experiment complied with the guidelines for the animal experimentation of Indian Council of Medical Research (ICMR) and was approved by the Institutional Animal Ethics Committee (IAEC) with CPCSEA registration number Rc.No. UEC/GMC/2016/9.

\section{Drugs used}

Tab. Fluoxetine 10mg, manufactured by Eli Lilly, Zinconia syrup manufactured by Zuventus and Tab. Ingavit B6 50mg manufactured by Inga Laboratories Pvt. Ltd were used in the study. Distilled water was used as control.

\section{Evaluation of anti-depressant activity}

The anti-depressant activity was measured using the forced swimming test (FST) also known as Porsolt's test after the developer of this model. ${ }^{8,9}$ This model works on principles of behavioral despair. FST involves the exposure of the animals to stress, which has shown to have a role in the tendency for major depression. ${ }^{10,11}$ In this test, the rats were forced to swim in a glass tank of dimensions $60 \mathrm{~cm}$ height, $30 \mathrm{~cm}$ width and $30 \mathrm{~cm}$ breadth, with no means of escape. It was done in two stages: the pre-test ( 24 hrs. before test) and the test.

During both the stages, after an initial period of struggle to escape, the rodents entered a state of despair and became immobile. The total duration of this immobility was measured in the study. The total duration of immobility was equated to state the behavioral despair.

Video cameras were placed directly above and to the side to record the proceedings. The test was performed for a total duration of 5 minutes, after which the rats were removed from the water and dried with towels, before being returned to their home cages. Each animal was considered immobile when it ceased to struggle or swim and, remained floating in the water, only to perform minimal movement to keep its head above water.

\section{Experimental design}

Eighteen albino wistar rats of 180-280 grams of either sex were procured from the Central Animal House, Gandhi Medical College. They were housed as consistent groups of six rats each (3 groups). Group 1 was control group which received only distilled water, group 2 was standard group which received fluoxetine and group 3 was test group which received zinc, vitamin B6 and fluoxetine. Free access to standard rodent diet and tap water was provided. A controlled temperature and a standard light/dark cycle was maintained. The rats were handled daily for a few minutes for four days, before initiating the behavioral testing. For preparation of pre-test, the rats were moved into the pre-test room, which also served as the test room. The pre-test (and test) was performed in a separate room from the storage room. They were left for about 1 hour after moving, to minimize the arousal caused by transportation.

The pre-test was performed at the same stage of the light/dark cycle as other experiments in the series. During pre-test, a glass tank of dimensions of $30 \mathrm{~cm}$ length, $30 \mathrm{~cm}$ breadth and $60 \mathrm{~cm}$ height, was filled to depth of $30 \mathrm{~cm}$ with water of temperature $23-25^{\circ} \mathrm{C}$. The pre-test was not recorded. It was done for a total duration of 15 minutes on each rat, after which the rats were removed from water, towel dried and shifted back to their home cages. The drugs used were distilled water, fluoxetine, zinc and vitamin B6. All drugs were given orally, 24 hours (immediately after pre-test), 5 hour and 60 minutes before the commencement of the test. The evaluation was performed at baseline i.e. on day 1 , on day 7 and on day 14. All the drugs were dissolved in distilled water. The animals which were weighed and selected before they were given weight specific dosages.

Video recording of each rat was done during the testing phase of the forced swim test. The parameters that were observed in the forced swim test were: 1. latency to the first immobility period (latency period) and 2. total duration of immobility (despair period). The values obtained from the videos, were analysed to yield the latency to immobility (the time taken from the start to the first-time onset of immobility) and the Total duration of immobility for individual rat.

\section{Statistical analysis}

The data obtained from the three groups was analysed using One-way analysis of variance (ANOVA) for each dependent variable while taking groups as the independent factor. The post hoc tests for multiple comparisons was done using Bonferroni test. Data analysis was done using IBM SPSS software, version 25.0 and $\mathrm{p}$ value $<0.05$ was considered statistically significant. 


\section{RESULTS}

Eighteen albino wistar rats of 180-280grams of either sex were used in this study. The rats were divided into three groups of six rats each. The groups $\mathrm{A}, \mathrm{B}$ and $\mathrm{C}$ were control, standard test respectively. The mean latency and despair periods were calculated and were analysed.

Table 1: The latency periods in the three groups.

\begin{tabular}{|llll|}
\hline \multirow{2}{*}{ Variables } & Groups & Standard (B) & Test (C) \\
\cline { 2 - 4 } & Control (A) & Mean \pm SD & Mean \pm SD \\
\hline Latency period on day 1 (in seconds) & Mean \pm SD & $268.83 \pm 30.16$ & $254.83 \pm 13.00$ \\
\hline Latency period on day 7 (in seconds) & $259.17 \pm 21.20$ & $126.17 \pm 22.33$ & $118.67 \pm 8.16$ \\
\hline Latency period on day 14 (in seconds) & $263.67 \pm 17.34$ & $125.33 \pm 11.86$ & $127.17 \pm 6.68$ \\
\hline
\end{tabular}

p value:- B vs C on days 7 and 14: $<0.001$, p value: B vs C on day 1: Not Significant; Data presented as mean \pm SD

Table 2: The despair periods in the three groups.

\begin{tabular}{|llll|}
\hline \multirow{2}{*}{ Variables } & Groups & Standard (B) & Test (C) \\
& Control (A) & Mean \pm SD & Mean \pm SD \\
\hline Despair period on day 1 (in seconds) & Mean \pm SD & $177.00 \pm 7.46$ & $167.17 \pm 14.82$ \\
\hline Despair period on day 7 (in seconds) & $167.17 \pm 18.23$ & $95.17 \pm 10.65$ & $97.33 \pm 7.63$ \\
\hline Despair period on day 14 (in seconds) & $171.33 \pm 20.79$ & $93.17 \pm 7.47$ & $87.50 \pm 4.18$ \\
\hline
\end{tabular}

p value:- B vs C on days 7 and 14: < 0.001, p value: B vs C on day 1: Not Significant; Data presented as mean \pm SD

The mean latency periods of the three groups have been tabulated in Table 1.

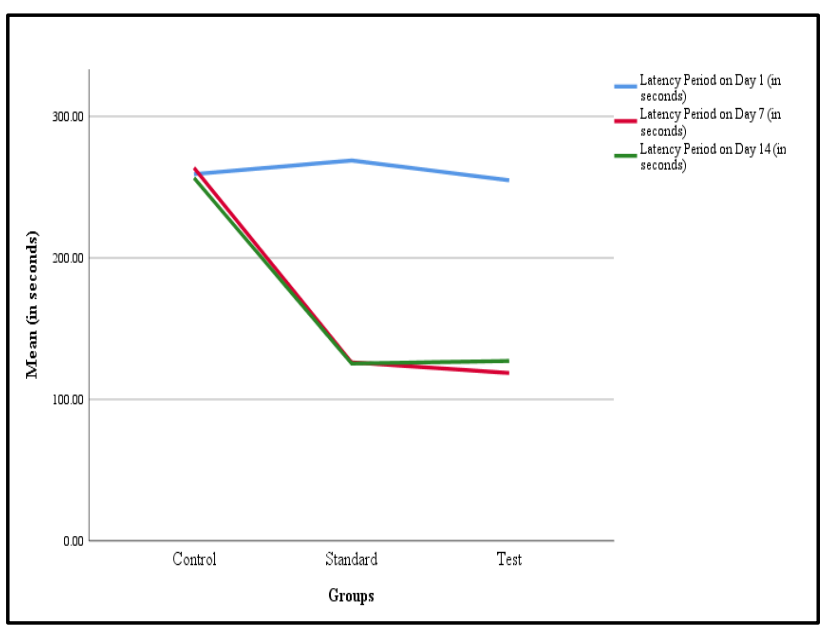

Figure 1: Trend chart of mean latency periods between the three groups.

It can be seen that the test group had statistically significant decrease $(\mathrm{p}<0.001)$ in latency period compared to control both on days 7 and 14. The rats of the standard and test groups had latency periods' means of $268.83 \pm 30.16$, $126.17 \pm 22.33$ and $125.33 \pm 11.86$ on $254.83 \pm 13.00$, $118.67 \pm 8.16$ and $127.17 \pm 6.68$ seconds on days 1,7 and 14 respectively. The trend chart of the means has been depicted in Figure 1. This indicates that rats receiving zinc and vitamin B6 supplementation have increased total duration of mobility compared to the group of rats receiving the standard treatment (group B) and the control (group A).

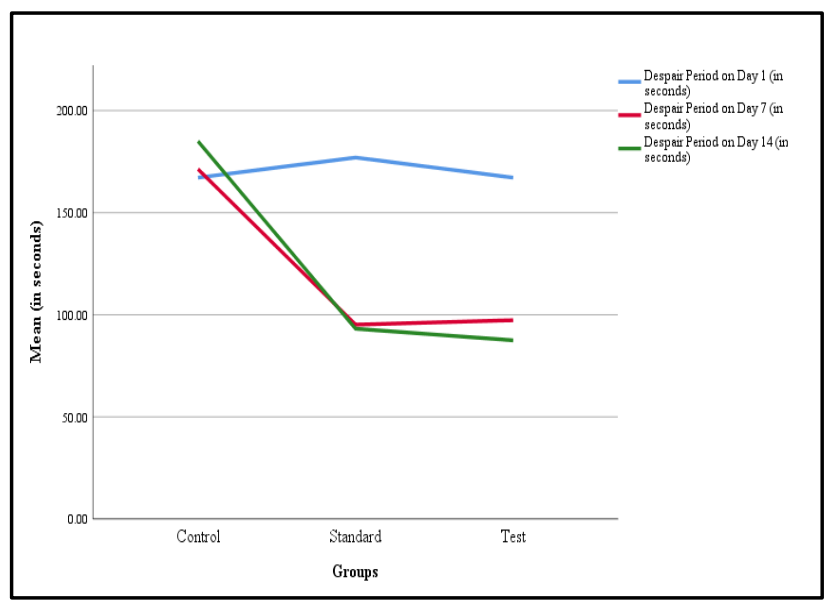

Figure 2: Trend chart of mean despair periods between the three groups.

The mean despair periods of the three groups have been tabulated in Table 2. The test group had statistically significant decrease $(\mathrm{p}<0.001)$ in despair period compared to control both on days 7 and 14. The rats of the standard and test groups had despair periods' means of $177.00 \pm 7.46$, $95.17 \pm 10.65,93.17 \pm 7.47$ and $167.17 \pm 14.82,97.33 \pm 7.63$ and $87.50 \pm 4.18$ seconds on days 1,7 and 14 respectively. 
The trend chart for the mean despair periods have been depicted in Figure 2. This indicates that rats receiving zinc and vitamin B6 supplementation swam for longer duration before entering the state of behavioral despair compared to the group of rats receiving the standard treatment (group B) and the control (group A).

\section{DISCUSSION}

In present study, it was found that supplementation of zinc and vitamin B6 to the standard treatment fluoxetine yielded better anti-depressant activity than fluoxetine alone as demonstrated by increase in latency and despair periods in rats subjected to stress using forced swim test.

Zinc is an essential trace element important for many biochemical and physiological processes related to brain growth and function, as well as cellular metabolism. ${ }^{12,13}$ Zinc is acquired through dietary intake of foods such as red meat, oysters and crab, and zinc deficiency can occur with reduced intake, insufficient absorption, and/or increased zinc utilization or expenditure. Normal serum zinc levels range from 0.66 to $1.10 \mu \mathrm{g} / \mathrm{mL}$ in adults. ${ }^{13}$ The balance of intracellular and extracellular zinc levels is crucial for maintaining zinc homeostasis in many brain regions, including those involved in the physiopathology of depression, such as the hippocampus, amygdala, and the cerebral cortex. ${ }^{14}$ The potential mechanisms underlying the association between low serum zinc and depression remain unclear, but may involve the regulation of neurotransmitter, endocrine and neurogenesis pathways. ${ }^{15}$ In the hippocampus and cortex, zinc ions regulate synaptic transmission or act as neurotransmitters, modulating many ligand- and voltage-gated ion channels. ${ }^{16-19}$ Disruption of zinc homeostasis in these regions has been implicated in many disturbances in cognition, behavioral and emotional regulation through mechanisms of decreased neurogenesis and neuronal plasticity. ${ }^{19-21}$ Zinc deficiency has also been implicated in the endocrine pathway of depression. Takeda et al, reported that a zinc-deficient diet induced high levels of serum cortisol concentration in rats. ${ }^{22}$ Persistently high levels of cortisol have been implicated in the development of depression via hyperactivity of the hypothalamicpituitary-adrenal (HPA) axis. ${ }^{23,24}$

Vitamin B6 (pyridoxine) is essential for amino acid metabolism, glucose metabolism, lipid metabolism, Hemoglobin synthesis and gene expression. The recommended daily intake is $1.3 \mathrm{mg} /$ day for adults. In the liver, pyridoxine and pyridoxal (an oxidized form) are phosphorylated by pyridoxal kinase to form pyridoxine- $\mathrm{P}$ and Pyridoxal 5-phosphate (PLP), the active cofactor form. PLP acts as a cofactor in the synthesis of neurotransmitters serotonin, dopamine, epinephrine, norepinephrine and $\gamma$ Amino Butyric Acid (GABA). ${ }^{4}$ Studies have demonstrated that supplementation of vitamin B6 reduces homocysteine blood levels and improves mood, psychotic symptoms in schizophrenia, fatigue, cognitive function and depression. ${ }^{24}$ In addition, reduced depressive symptoms were evident following four weeks of pyridoxine administration in schizophrenic patients. ${ }^{24}$ The results of our study are similar to that done by Azadeh et al, where they concluded that vitamin B6 supplementation reduced depression in mouse models when used as an adjuvant to standard anti-depressant medication. ${ }^{6}$

\section{CONCLUSION}

In conclusion, zinc and vitamin B6 supplementation to the standard care of treatment in depression would give better response and would give promising results in patients with depression.

\section{Funding: No funding sources \\ Conflict of interest: None declared \\ Ethical approval: The study was approved by the Institutional Ethics Committee}

\section{REFERENCES}

1. Depression. Available at: http://www.who.int/en/news-room/factsheets/detail/depression. Accessed on 25th October 2018.

2. Cornish S, Mehl-Madrona L. The role of vitamins and minerals in psychiatry. Integrative Medicine Insights. 2008 Jan;3.

3. Sandstead HH, Frederickson CJ, Penland JG. History of zinc as related to brain function. J Nutrition. 2000 Feb 1;130(2):496S-502S.

4. Mikkelsen K, Stojanovska L, Apostolopoulos V. The effects of vitamin B in depression. Current Med Chem. 2016 Nov 1;23(38):4317-37.

5. Takeda A, Hirate M, Tamano H, Oku N. Release of glutamate and GABA in the hippocampus under zinc deficiency. J Neurosci Res. 2003 May 15;72(4):53742.

6. Mesripour A, Hajhashemi V, Kuchak A. Effect of concomitant administration of three different antidepressants with vitamin B6 on depression and obsessive compulsive disorder in mice models. Res Pharmaceutical Sci. 2017 Feb;12(1):46-52.

7. Martin SJ, Grimwood PD, Morris RG. Synaptic plasticity and memory: an evaluation of the hypothesis. Annual Rev Neurosci. 2000 Mar;23(1):649-711.

8. Porsolt RD, Le Pichon M, Jalfre ML. Depression: a new animal model sensitive to antidepressant treatments. Nature. 1977 Apr;266(5604):730-2.

9. Porsolt RD, Bertin A, Jalfre M. Behavioral despair in mice: a primary screening test for antidepressants. Int Arch Pharmacodynamics Therapy. 1977 Oct;229(2):327-36.

10. Caspi A, Sugden K, Moffitt TE, Taylor A, Craig IW, Harrington $\mathrm{H}$, et al. Influence of life stress on depression: moderation by a polymorphism in the 5HTT gene. Science. 2003 Jul 18;301(5631):386-9.

11. Kaufman J, Yang BZ, Douglas-Palumberi H, Grasso D, Lipschitz D, Houshyar S, et al. Brain-derived neurotrophic factor-5-HTTLPR gene interactions and 
environmental modifiers of depression in children. Biol Psychiatry. 2006 Apr 15;59(8):673-80.

12. Jurowski K, Szewczyk B, Nowak G, Piekoszewski W. Biological consequences of zinc deficiency in the pathomechanisms of selected diseases. JBIC Journal of Biological Inorganic Chem. 2014 Oct 1;19(7):106979.

13. Szewczyk B, Kubera M, Nowak G. The role of zinc in neurodegenerative inflammatory pathways in depression. Progress Neuro-Psychopharmacol Biol Psychiatry. 2011 Apr 29;35(3):693-701.

14. Maserejian NN, Hall SA, McKinlay JB. Low dietary or supplemental zinc is associated with depression symptoms among women, but not men, in a population-based epidemiological survey. J Affective Dis. 2012 Feb 1;136(3):781-8.

15. Wang J, Um P, Dickerman BA, Liu J. Zinc, Magnesium, Selenium and Depression: a review of the evidence, potential mechanisms and implications. Nutrients. 2018;10.

16. Huang EP. Metal ions and synaptic transmission: think zinc. Proceed National Acad Sci. 1997 Dec 9;94(25):13386-7.

17. Chen N, Moshaver A, Raymond LA. Differential Sensitivity of RecombinantN-Methyl-D-Aspartate Receptor Subtypes to Zinc Inhibition. Molecular Pharmacol. 1997 Jun 1;51(6):1015-23.

18. Kalappa BI, Anderson CT, Goldberg JM, Lippard SJ, Tzounopoulos T. AMPA receptor inhibition by synaptically released zinc. Proceed National Acad Sci. 2015 Dec 22;112(51):15749-54.

19. Marchetti C. Interaction of metal ions with neurotransmitter receptors and potential role in neurodiseases. Biometals. 2014 Dec 1;27(6):1097113.

20. Gao HL, Zheng W, Xin N, Chi ZH, Wang ZY, Chen $\mathrm{J}$, et al. Zinc deficiency reduces neurogenesis accompanied by neuronal apoptosis through caspasedependent and-independent signaling pathways. Neurotoxicity research. 2009 Nov 1;16(4):416-25.

21. Pfaender S, Föhr K, Lutz AK, Putz S, Achberger K, Linta L, et al. Cellular zinc homeostasis contributes to neuronal differentiation in human induced pluripotent stem cells. Neural plasticity. 2016;1-5.

22. Takeda A, Tamano H, Ogawa T, Takada S, Ando M, Oku N, Watanabe M. Significance of serum glucocorticoid and chelatable zinc in depression and cognition in zinc deficiency. Behavioural Brain Res. 2012 Jan 1;226(1):259-64.

23. Jokinen J, Nordström P. HPA axis hyperactivity and attempted suicide in young adult mood disorder inpatients. J Affective Dis. 2009 Jul 1;116(1-2):11720.

24. Pariante CM, Lightman SL. The HPA axis in major depression: classical theories and new developments. Trends Neurosci. 2008 Sep 1;31(9):464-8.

Cite this article as: Sunitha T, Prabhat G, Kishore $\mathrm{K}$, Madhavi LV. Evaluation of anti-depressant activity of zinc and vitamin B6 as adjuvants to fluoxetine in an animal model of depression. Int J Basic Clin Pharmacol 2018;7:2359-63. 